\title{
Reseña \\ Brecht en la Ciudad de la Fruta. Una aproximación al teatro épico. ${ }^{1}$
}

\author{
Carolina Castro Ibáñez \\ Doctoranda Pontificia Universidad Católica de Chile² \\ Javiera Castro Ibáñez \\ Universidad Mayor
}

La Ciudad de la Fruta es una obra autobiográfica de la dramaturga chilena Leyla Selman, montada en el Teatro de la Memoria. Esta es una obra en la cual se narra la historia de abusos infantiles que Leyla sufrió en el tiempo histórico de la dictadura militar en Chile. En la narración, se expone el enfrentamiento entre una mujer adulta y los cuatro hombres que abusaron de ella durante su infancia. Se dispone en escena un ejercicio de representación de una obra de teatro a través de la cual, ella va a ser "sanada" de este trauma que la ha perseguido hasta la adultez. En palabras de su director Rodrigo Pérez, "hay poesía en la visualidad, es una invitación a contemplar un espectáculo que usa la belleza para contar y denunciar el horror. Es un trabajo que abarca temáticas muy actuales como el abuso, el feminismo y la salud mental"3. En función de lo anterior, surge la inquietud ¿Qué aspectos escénicos de "La Ciudad de la Fruta" son posibles de vincular con el teatro épico de Bertolt Brecht?

Al situarme desde una mirada brechtiana lo primero que me surge es como esta obra desde su narración, logra "mostrar lo que sucede detrás de los sucesos" (Brecht 38). En particular, se muestran los padecimientos traumáticos infantiles debido a las interacciones no consentidas entre una niña y un adulto y esto "sucede así ahora, desde hace mucho, pero no ha sucedido así, por ejemplo, siempre" (Brecht 38), en tanto si nos remontamos a épocas antiguas el abuso sexual infantil no era considerado un abuso, si no más bien una práctica naturalizada de relaciones sexuales que podían darse entre niños y adultos. Por ejemplo, en Chile al inicio del siglo XX era común escuchar de matrimonios entre niñas de 12 y 13 años con hombres de 30. En la actualidad ese tipo de relaciones ya no son permitidas y se encuentran normadas por discursos que sitúan al hombre como pedófilo y a la niña como víctima de abuso. Con ello, puedo vincular el efecto distanciador de Brecht, toda vez que "el objeto del efecto distanciador es distanciar el gesto social que subyace a todos los sucesos. Bajo gesto social entendemos la expresión gestual y mímica de las relaciones sociales, que rigen en determinada época la convivencia entre los hombres" (136).

En este sentido, la obra tiene la doble intención de hacernos conscientes sobre el abuso, pero también sobre lo que esconden ciertas "enfermedades psiquiátricas" que al correr el velo del pasado puede mostrar el origen desgarrador de estas. Un objetivo de ello, es hacernos conscientes o, bien, sacarnos de nuestro inconsciente respecto a estas temáticas, Piscator y también programáticamente por Bagner han denominado esta forma de utilización del arte "como instrumento de concienciación" (Sánchez 2002).

\footnotetext{
${ }^{1}$ Trabajo en el marco del proceso formativo de Javiera Castro.

2 c.castro.i@uc.cl

${ }^{3}$ Recuperado de culturizarte.cl
} 
Asimismo, otro aspecto que puedo vincular el distanciamiento de Brecht con la obra, se produce al comienzo de esta cuando Marcela -quien se presenta como la terapeuta- indica que va a dirigir la sesión para "ella" -nombre ficticio de la actriz que representa a Leyla- a través de "una obra dentro de una obra" y para ello, no solo mira hacia el público, sino además, nos explica y nos habla directamente a nosotros, haciéndonos presente de lo que va suceder. Su intención es que el público entienda que esto no es para entrar en la ilusión de un teatro, si no, que esto es una obra de teatro, parte de la realidad, pero no una realidad absoluta, en la que se busca que el espectador no sea "transportado, o secuestrado, de su mundo al mundo del arte; por el contrario, debería ser introducido en su mundo real, con todos los sentidos despiertos" (Brecht 83). De igual modo, "Ella" al narrarnos sobre los abusos que sufrió lo hace situándose frente al público, mirándonos directamente, rompiendo con "la cuarta pared ficticia que separa el escenario del público" (Brecht 131) y donde más que actuar el abuso interesa narrarnos las relaciones inadecuadas desde la óptica de lo impregnado en la memoria de "Ella".

De acuerdo con los términos vistos en clases referidos al distanciamiento, la elección de determinados recursos escénicos para narrarnos esta historia, son determinantes para el conflicto que se quiere abordar y con ello, "la forma escénica determina la forma dramática de la obra" (Sánchez 2002). En particular los recursos de la obra determinan una atmósfera fría tenue e inexpresiva para el espectador. Lo que me pasó como espectadora, es que la luz como parte de estos recursos que generan distanciamiento guio mi atención focalizándome en "Ella", teniendo una idea preconcebida de lo que iba a relatar, sin embargo, en su último testimonio sólo dice, "de este hombre no hablaré porque me quitó todo" lo que con la ayuda de la luz y el espacio brindado por "ella" -al no mostrar lo evidente- me permitió asombrarme y, al mismo tiempo, tomar una postura analítica y crítica frente a lo representado (Benjamín; Brecht ). Al respecto, la dramaturga Coca Duarte en el Seminario escenas reales 11 señaló que, "el capítulo más traumático quedó fuera de la producción escénica, sin embargo, puede imaginarse por el espectador", lo que en palabras de Sánchez sería que "Una vez más el teatro se plantea como objetivo la manifestación de lo inexpresable; lo inexpresable es el mito. O más bien. El origen del contenido de los mitos a partir de la experiencia personal"

Dentro de la obra también hay elementos gestuales que Brecht, define como "gestus" que están en, por y para el espectador, ya que estos gestos son los que permiten hacer análisis y síntesis con los diferentes elementos que nos presentan dentro de una obra. "Para Brecht, el lenguaje de la escena no era la palabra, ni la acción, si no el gesto, que contenía a ambas. El gesto era lo que debía ser transmitido, porque era el gesto lo que debía ser escenificado" (Sánchez 2002). En el caso particular de esta obra, cuando "ella" aparece en el escenario inmediatamente vemos a una mujer absolutamente traumatizada, pero no es su vestuario el que define este análisis, si no, los gestos que ella como actriz decidió seleccionar a través de su propio estudio y observación de las diferentes mujeres que pueden haber tenido en su vida la experiencia de una violación, gestos que le permiten a ella entender y abordar este personaje. Esta selección tiene que ver precisamente con una reflexión que ella también dispondrá en escena, es decir, cada gesto que ella elige no está elegido por que sí, más bien es una invitación al espectador a leerla. "Ella" elige tres gestos: el primero, un leve movimiento con sus pies que la mantienen en constante inclinación y descenso, sube y baja todo el tiempo desde sus talones; segundo, sus manos se mantienen escondidas detrás de su espalda, o bajo el chaleco y cuando las tiene a los lados del torso con sus dedos toca sus yemas constantemente y tercero, cada vez que transita dentro de la escena ella con sus manos se toca el cabello crespo y suelto como si fuese a retocarlo con un movimiento que lo mantiene con 
constante frizz y poco ordenado. Con estos gestos, se hace posible vincular la obra con elementos del drama épico en tanto, "medio artístico de la índole más sutil, convirtiéndose en el caso especial de la pieza didáctica en uno de los fines más próximos (Benjamín 37).

Al igual que lo anterior, cuatro hombres en escena que personifican a los "abusadores" interrumpen con gestos en una velocidad rápida, que llevaban a cabo cada cierto momento, que repetían y efectuaban con diferentes posturas corporales o "muletillas" que los iban definiendo y caracterizando. Estos gestos son los que en palabras de Coca Duarte "son los gestos que quedaron fijos en la memoria de ella" siendo los recuerdos manifiestos a través de sus reacciones físicas (Sánchez 2002). Como se trata de relatar momentos que se reproducen en ella a modo de recuerdo, y estos recuerdos queremos llevarlos a escena para poder personificarlos y actuarlos para así poder evidenciarlos, y permitir el sanar a través del actuar, interrumpiendo las acciones, creando nuevas imágenes sin una ilación lógica, relatando y recortando, dándole un giro que permite acercarlo al collage, donde "a través de este tipo de operaciones, las artes escénicas se han adentrado en la lógica atea del flujo y la transformación, promoviendo arreglos experimentales que hacen proliferar diversas capas de sentido, lo que les permite desestructurar las formas de comprensión tradicionales, abrir nuevos canales para la interpretación y alcanzar algunos destellos de aquella realidad que excede los límites de lo pensable, lo que, desde nuestra perspectiva, convierte al collage en un recurso que ha permitido que los artistas contemporáneos continúen interrogando nuestra compleja relación con la realidad" (Morales 105).

Cabe señalar que en la obra Marcela que es terapeuta de "Ella" se acomodan en un costado derecho de la sala, cada una en una silla. "Ella" está sentada con sus pies y manos cruzadas, las manos encima de su falda larga, su espalda erguida y la mirada perdida. Marcela, quien está sentada al lado de ella con una pierna encima de la otra, los brazos abiertos y la mirada hacia en algún punto de la muralla que está detrás de las butacas de los espectadores, luego de un momento Marcela comienza a realizar los mismos movimientos que hace "Ella" como a modo de espejo, se refleja para nosotros una imagen doble, las dos se unen y el gesto de "ella" también es el de Marcela. Y de esto puedo deducir que, así como "Ella" ha sido violentada sexualmente, también así podría serlo Marcela, como también puedo serlo yo, como también mi hermana que está sentada a mi costado derecho, como también la mujer que está en la boletería del teatro, o la que en la calle está esperando su taxi en este momento. Así como fue "Ella" fuimos todas. Y así como le paso a "Ella", nos podría suceder a todas.

Lo interesante de analizar esta obra con los postulados de Brecht, ha sido entender que como es una especie de terapia la que se está llevando a cabo en escena, le da un efecto y un peso diferente, porque las terapias de por si son muy intensas teniendo como principal dificultad el pedirle a la persona en terapia que pueda contar todo aquello que no le permite vivir para así poder sanar. Entonces, utilizar el método de la actuación como una medida de sanación me permite como espectador desde ya tener una mirada diferente al sentarme a ver esta obra. Incluso para el mundo del arte abre posibilidades a nuevos y diferentes métodos de trabajo psicológico con situaciones que son extremadamente delicadas de abordar, tal como señala Susan Sontag "el teatro consiste en la revelación de un personaje, construido a partir de un conflicto de motivos que sean verosímiles desde un punto de vista realista. Pero el teatro moderno más interesante es un teatro que va más allá de la psicología" (189). 
CAROLINA CASTRO. • Brecht en la Ciudad de la Fruta. Una aproximación al teatro épico.

Finalmente, es fundamental comprender el teatro desde los aportes de Brecht como un método de enseñanza, cuestionamiento y aprendizaje tanto para quienes están en escena como para los están observando, pudiendo ser abordado de diferentes maneras; en la puesta en escena como actoral, volviéndolo entretenido y experiencial. 


\section{Bibliografía}

Benjamin, Walter. "Tentativas sobre Brecht. Iluminaciones III”. Madrid, España: Taurus, 1999. Impreso.

Brecht, Bertolt. "Escritos sobre teatro". Barcelona, España: Alba, 2004. Impreso.

Morales, Alejandra. "La operación collage-montaje como punto de encuentro entre las artes visuales y las artes escénicas contemporáneas". Revista de Teoría del Arte, (30) 2016: 99 108. Consultado

de: https://revistateoriadelarte.uchile.cl/index.php/RTA/article/view/46428/48457

Sánchez, José. Dramaturgias de la imagen. Cuenca: Edición de la Universidad de Castilla La Mancha, 2002. Impreso.

Sontag, S. (1966). “Marat / Sade / Artaud". Edición original: Against interpretation and other Essays.

Recibido:19 de Octubre de 2019

Aceptado: 1 de Noviembre de 2019 